\title{
Acute Quadriplegic Myopathy Unrelated to Steroids or Paralyzing Agents: Quantitative EMG Studies
}

\author{
Ahmet Höke, N. B. Rewcastle and Douglas W. Zochodne
}

\begin{abstract}
Background: Quadriplegic myopathy (QM) and its variants generally are described in critically ill patients who are exposed to steroids and nondepolarizing muscle blocking agents (NDMBAs). Methods: A patient with sepsis who was not exposed to steroids or an NDMBA infusion developed QM and was studied using serial quantitative electromyography. Results: Clinical and electrophysiological studies identified evidence of a severe myopathy and muscle biopsy showed necrosis, calcifications and selective loss of myosin filaments in non-necrotic fibers. Her clinical recovery paralleled rises in motor unit action potential (MUAP) amplitudes studied by serial automatic decomposition electromyography (ADEMG). Conclusions: QM can develop with sepsis and without significant exposure to steroids and NDMBAs. ADEMG can be a useful tool in electrophysiological evaluation of critically ill patients with weakness.
\end{abstract}

RÉSUMÉ: Myopathie quadriplégique aiguë sans relation avec l'administration de stéroïdes ou avec d'agents paralysants: études ÉMG quantitatives. Introduction: La myopathie quadriplégique (MQ) et ses variantes sont généralement décrites chez des patients dont l'état est critique et qui sont exposés à des stéroïdes et à des bloquants musculaires non dépolarisants (BMNDs). Méthodes: Une patiente atteinte de septicémie, qui n'avait pas été exposée à des stéroïdes ou à une perfusion de BMND, a développé une MQ. Nous avons procédé chez cette patiente à une étude électromyographique quantitative sériée. Résultats: Les études cliniques et électrophysiologiques ont montré des manifestations de myopathie sévère, et à la biopsie musculaire, on a observé une nécrose, des calcifications et une perte sélective des filaments de myosine dans les fibres qui n'étaient pas nécrotiques. Sa récupération clinique a été parallèle à l'augmentation de l'amplitude des potentiels d'action des unités motrices notée à l'électromyographie de décomposition automatique sériée (ÉMGDA). Conclusions: Une MQ peut survenir chez les patients septiques, sans exposition significative à des stéroïdes et à des BMNDs. L'ÉMGDA peut être un outil précieux dans l'évaluation électrophysiologique de patients en état critique qui présentent de la faiblesse musculaire.

Can. J. Neurol. Sci. 1999; 26: 325-329

Quadriplegic myopathy (QM) is a recently recognized clinical entity with characteristic clinical and histopathological features. In 1977 MacFarlane and Rosenthal reported development of a reversible acute severe myopathy in a patient with status asthmaticus. ${ }^{1}$ In the 1980 s various authors reported similar cases and noticed an association between QM and exposure to high doses of corticosteroids and NDMBAs. In 1991 Danon and Carpenter reported a characteristic selective loss of myosin filaments. ${ }^{2}$ Most patients with QM are critically ill, requiring prolonged periods of mechanical ventilation. Almost all of the patients reported in the literature were exposed to high doses of corticosteroids due to their underlying medical condition and over 90 percent had exposure to NDMBAs. Here we report development of acute QM in a patient who was critically ill but had no exposure to corticosteroids or NDMBA infusion.

\section{Case Report}

A 63-year-old woman developed septic shock due to a perforated bowel after a debulking procedure for recurrent ovarian granulosa cell tumor. Within a few days she developed adult respiratory distress syndrome and high output renal failure because of acute tubular necrosis. A serum creatine kinase measurement on postoperative day 1 was elevated $(1081 \mathrm{U} / \mathrm{L})$ but returned to normal within two weeks. In the following three weeks after her surgery she received two single doses of pancuronium $(6 \mathrm{mg}), 1$ week apart, but no infusion. She was not exposed to any exogenous corticosteroids and there was no clinical evidence of high endogenous corticosteroid production. At four weeks as she was

\footnotetext{
From the Departments of Clinical Neurosciences (AH, DWZ) and Pathology (NBR), University of Calgary, Calgary, Canada.

RECEIVED NOVEMBER 3, 1998. ACCEPTED IN FINAL FORM APRIL 20, 1999 Reprint requests to: D. W. Zochodne, University of Calgary, Dept of Clinical Neurosciences, HMRB 182A, 3330 Hospital Dr. NW, Calgary, Alberta, Canada T2N $4 \mathrm{~N} 1$
} 
Table 1: Motor Conduction Studies

\begin{tabular}{|c|c|c|c|c|c|c|c|c|}
\hline Dates: & \multicolumn{2}{|c|}{ Median } & \multicolumn{2}{|c|}{ Ulnar } & \multicolumn{2}{|c|}{ Peroneal } & \multicolumn{2}{|c|}{ Tibial } \\
\hline Post-op day \#48 (20) & 3.7 & 47 & 4.7 & 51 & 1.4 & 43 & 5.7 & 47 \\
\hline Post-op day \#157 (129) & 6.6 & 57 & 7.6 & 62 & 3.8 & 49 & 8.1 & 47 \\
\hline
\end{tabular}

Three separate nerve conduction studies were done. On the initial evaluation all motor nerves showed marked reduction in amplitudes which recovered over time. Conduction velocities were normal. Days in parentheses denote the days after she was noted to be quadriparetic.

(Amp: M potential amplitude, CV: conduction velocity)

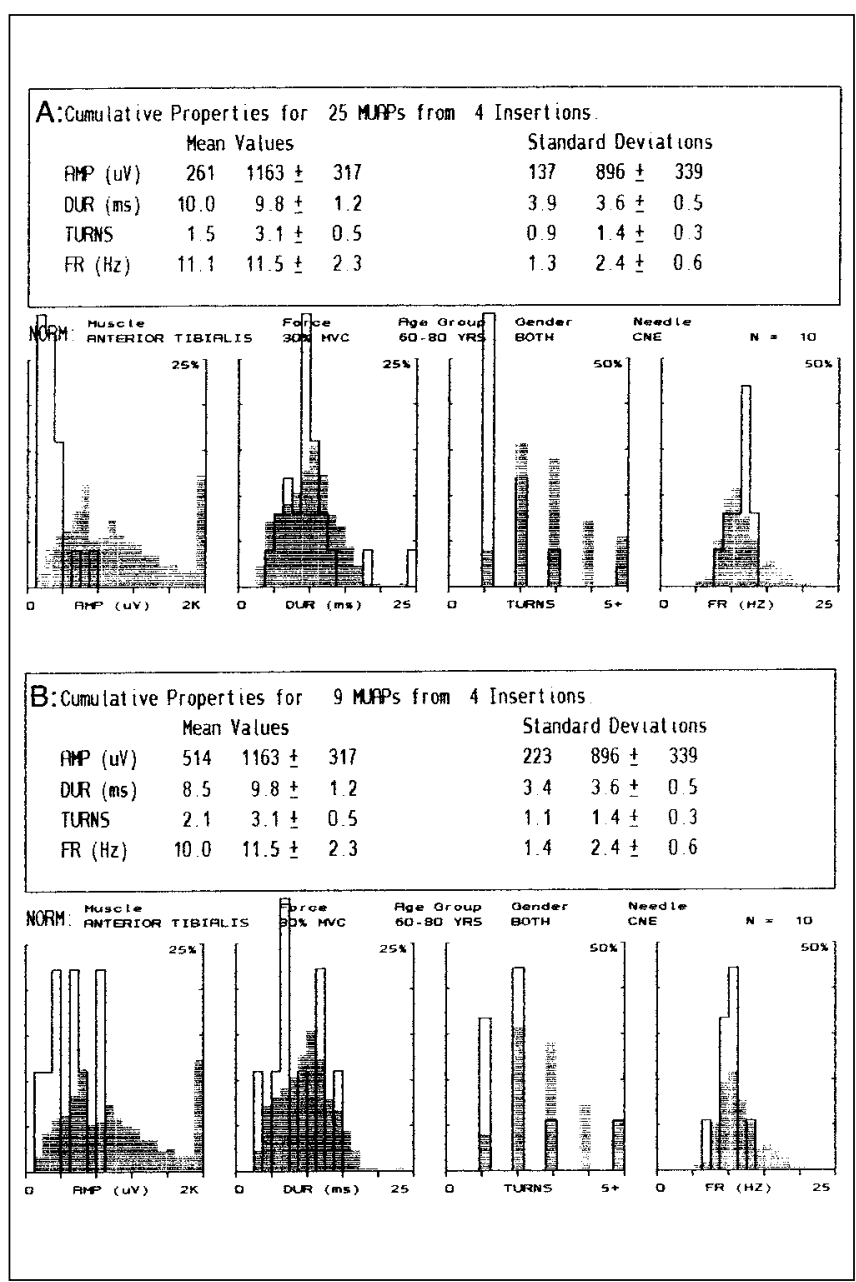

Figure 1: Computer printouts of two separate ADEMG studies. The first one was done immediately when the patient was noted to be weak $(\boldsymbol{A})$ and second was done four months later when she had fully recovered $(\boldsymbol{B})$. During the initial study mean MUAP amplitudes were severely reduced $(261 \mu V)$ compared to age, muscle and force of contraction matched controls $(1163 \mu \mathrm{V})$. In the repeat study, the mean MUAP amplitudes improved but only partially $(514 \mu \mathrm{V})$, although the patient seemed to have full clinical recovery. (Open bars on the histogram denote the patient's MUAPs and the hatched bars are normative data). recovering, but still intubated, she was noted to be quadriparetic. The exact onset of her weakness was unclear because of prior sedation. On examination, she had significant limb edema. She was intubated, but fully oriented. There was mild bilateral facial weakness but no other cranial nerve abnormalities. She had mild diffuse wasting and moderate to severe quadriparesis $(1 / 5-2 / 5$ proximally and $3 / 5-4 / 5$ distally on the MRC scale). She had reduced reflexes in both biceps brachii and triceps, and absent reflexes in her brachioradialis, quadriceps femoris and triceps surae. The sensory examination was normal. The first set of electrophysiological studies were done the same day and she had a muscle biopsy done the next day. Within a month she started to recover and was fully recovered by four months. Repeat electrophysiological studies were done three weeks and four months after the initial recognition of her weakness.

\section{METHODS}

Electrophysiological recordings were done using standard techniques and were supervised by a single electromyographer (D.W.Z.). Needle electromyography was done using concentric needles and quantitative MUAP assessment was done with the automatic decomposition electromyography (ADEMG) protocol $^{3}$ using a Viking IV machine (Nicolet Biomedical Inc., Madison, WI). Muscle biopsy of the left deltoid was prepared using standard methods and staining procedures for frozen section, paraffin and epoxy resin analysis, the latter also including electron microscopy study.

\section{RESUlts}

Standard nerve conduction studies showed normal conduction velocities for median, ulnar, peroneal, tibial and sural nerves. However, during the initial evaluation the $\mathrm{M}$ potential amplitudes in median, ulnar, peroneal and tibial territories were reduced (Table 1). These values improved on subsequent studies. The sensory conduction studies were borderline reduced in amplitude but this was felt to be due to severe limb edema although a direct effect of sepsis on the sensory nerves could not be excluded (Table 2). Repetitive conduction studies did not identify any abnormalities. On concentric needle electromyography, there was no spontaneous activity in the form of fibrillation potentials or positive sharp waves in left tibialis anterior, vastus medialis, first dorsal interossei and triceps muscles. However, both proximal and distal muscles had MUAPs that were markedly reduced in 


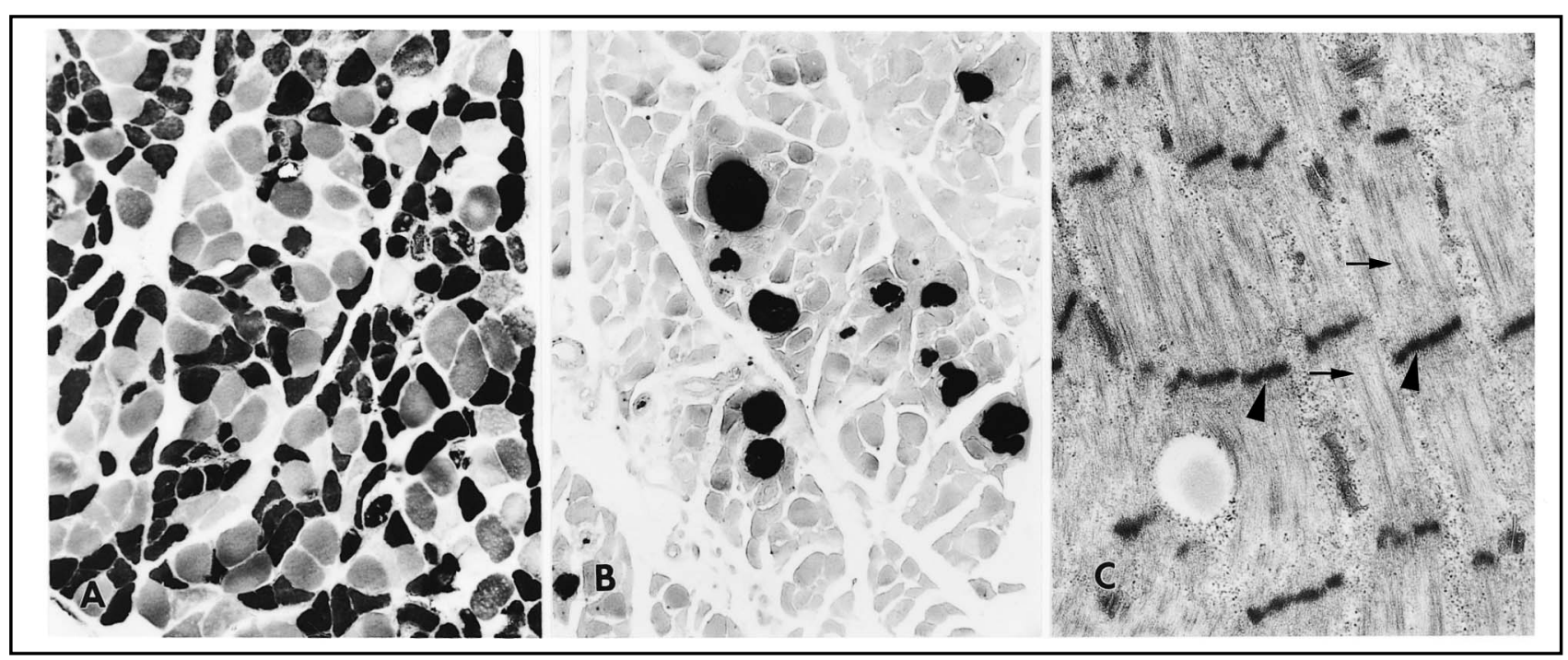

Figure 2: Muscle biopsy of left deltoid. (A): ATPase (pH 4.7) stain of frozen sections demonstrates a predominance of type 1 fibers (darkly stained) without grouping. Some fibers showed lack of staining suggestive of loss of myofibrillar network and necrosis (100X). (B): There were significant numbers of calcifications (darkly stained profiles) distributed throughout the muscle within a background of active degeneration and regeneration (stained with Alizarin Red S to show calcium deposits, 100X). (C): Electron microscopy showing areas of muscle with preserved Z-bands (arrowheads) and relative loss of myosin filaments (arrows). (15,000X)

amplitude and duration indicating evidence of a severe myopathic process. ADEMG analysis of the left tibialis anterior muscle verified these findings, demonstrating reductions in the amplitudes of MUAPs compared to age-matched controls (Figure 1A). Repeat examination four months later, identified recovery in MUAP amplitudes by standard needle electromyography and ADEMG criteria but MUAPs were still reduced compared to age-matched controls (Figure 1B).

The muscle biopsy showed marked structural changes in up to $25 \%$ of fibers in some fascicles. Most pronounced was evidence of active regeneration with basophilia and vesicular nuclei, but also present was fiber necrosis with macrophage infiltration and foci of calcification within myotubes (Figure 2B). ATPase reactions demonstrated a predominance of type 1 fibers without grouping. Some fibers showed lack of staining in ATPase reactions suggestive of loss of myofibrillar network (Figure 2A). Electron microscopy showed areas of muscle with preserved Z-bands and relative loss of myosin filaments in nonnecrotic fibers (Figure 2C).

\section{Discussion}

Causes of muscle weakness in critically ill patients are varied but include a significant number of patients with neuromuscular diseases. Among these neuromuscular diseases, QM is often unrecognized and underdiagnosed. Numerous synonyms have been used in the literature. These include myopathy with thick filament loss, ${ }^{2}$ acute hydrocortisone myopathy, ${ }^{4}$ necrotizing myopathy of intensive care, ${ }^{5-8}$ acute relaxant-steroid myopathy ${ }^{9}$ and blocking agent-corticosteroid myopathy. ${ }^{10}$ In recent years, some of the relative risk factors have been identified, and these include exposure to high doses of corticosteroids and prolonged use of NDMBAs; however, not all patients had exposure to both. Some of the cases in the literature only had exposure to high doses of corticosteroids ${ }^{11-13}$ and some only had prolonged uses of NDMBAs. ${ }^{7,13,14}$ Our patient suggests that critically ill patients may develop a similar myopathy without significant exposure to either of these risk factors.

Since QM is a relatively new clinical entity, there is a confusion over the definition and, therefore, the diagnosis of this

Table 2: Sensory Conduction Studies

\begin{tabular}{|c|c|c|c|c|c|c|c|c|}
\hline \multirow[b]{2}{*}{ Dates } & \multicolumn{2}{|c|}{ Median } & \multicolumn{2}{|c|}{ Ulnar } & \multicolumn{2}{|c|}{ Radial } & \multicolumn{2}{|c|}{ Sural } \\
\hline & $\operatorname{Amp}(\mathrm{uV})$ & $\mathrm{CV}(\mathrm{m} / \mathrm{s})$ & $\operatorname{Amp}(\mathrm{uV})$ & $\mathrm{CV}(\mathrm{m} / \mathrm{s})$ & $\operatorname{Amp}(\mathrm{uV})$ & $\mathrm{CV}(\mathrm{m} / \mathrm{s})$ & Amp (uV) & $\mathrm{CV}(\mathrm{m} / \mathrm{s})$ \\
\hline Post-op day \#30 (2) & 18 & 61 & 17 & 52 & 13 & 58 & 1.6 & 48 \\
\hline Post-op day \#48 (20) & 34 & 46 & 39 & 50 & ND & ND & 8.3 & 33 \\
\hline Post-op day \#157 (129) & 37 & 57 & 45 & 56 & ND & ND & 5.1 & 46 \\
\hline
\end{tabular}

Normals: Median: Amp $>20 \mu \mathrm{V}, \mathrm{CV}>49 \mathrm{~m} / \mathrm{s}$

Ulnar: Amp $>17 \mu \mathrm{V}, \mathrm{CV}>49 \mathrm{~m} / \mathrm{s}$

Radial: Amp $>15 \mu \mathrm{V}, \mathrm{CV}>49 \mathrm{~m} / \mathrm{s}$

Sural: Amp $>6 \mu \mathrm{V}, \mathrm{CV}>39 \mathrm{~m} / \mathrm{s}$

Sensory nerve conduction studies were done using antidromic technique. On the initial evaluation all sensory nerves showed borderline abnormalities in amplitudes which recovered over time. These borderline abnormalities were felt to be due to limb edema. Conduction velocities were normal. Days in parentheses denote the days after the patient was noted to be quadriparetic. (Amp: SNAP amplitude, CV: conduction velocity) 
illness. Often these patients are very ill and the clinical assessment is clouded by sedation and encephalopathy. Electrophysiological studies are invaluable in arriving at the correct diagnosis. In our patient, the features of myopathy were: (i) decreased $\mathrm{M}$ potentials with rapid recovery accompanying clinical improvement, (ii) preserved sensory conduction, (iii) lack of abnormal spontaneous activity, and (iv) motor unit potential configurations compatible with myopathy rather than denervation with reinnervation. Lack of abnormal spontaneous activity in this myopathic condition may be in keeping with other reports which showed that the muscle is inexcitable when stimulated directly. ${ }^{15,16}$ In addition, unlike previous reports, we made serial quantitative motor unit potential analyses allowing comparison with age, muscle and degree of contraction-matched normals. ADEMG verified that the findings were diagnostic of myopathy, later confirmed by biopsy.

Evaluation of muscle biopsy is the gold standard in arriving at the correct diagnosis of QM. There may be confounding factors, however, in the proper interpretation, such as the presence of concomitant type II fiber atrophy from prolonged inactivity, and the variations in the pathological findings depending on timing of the biopsy. The findings that are relatively specific for this illness include atrophy of both fiber types with selective loss of myosin filaments on electron microscopy. However, these changes often are not present uniformly throughout the specimen and depend on when the biopsy is taken. Lacomis et al. found that the selective loss of myosin filaments were present in biopsies taken four weeks after the corticosteroid exposure but not in biopsies taken within the first two weeks of the corticosteroid infusion. ${ }^{8}$ In severe cases, muscle fiber necrosis may obscure the myosin loss. ${ }^{6}$ One other unique feature of our patient's biopsy was the presence of extensive calcifications. Although a nonspecific feature of muscle injury, this finding has not been reported in QM before.

The pathogenesis of QM is unknown. Exposure to steroids in combination with physical or physiological denervation (e.g. prolonged neuromuscular blockade) has been proposed as a possible mechanism. ${ }^{17}$ This hypothesis is also supported by studies which showed diffuse and focal reduction in myosin staining in denervated muscles of rats exposed to high dose steroids. ${ }^{18}$ Our patient, however, did not have any exposure to exogenous steroids. It is possible that two single doses of pancuronium may have created a physiological denervation because of prolonged half-life due to renal insufficiency. This is unlikely because pancuronium is cleared by both hepatic and renal systems and even in complete renal insufficiency the halflife is only doubled to 2-5 hours after single injection. ${ }^{19}$ As an alternative mechanism of pathogenesis, loss of thick filaments have been linked to myosin degradation due to activation of the ATP-ubiquitin proteolytic process. ${ }^{20}$

The important feature of this patient was that the condition developed in conjunction with septic shock. Sepsis and the associated systemic inflammatory response have been associated with another common neuromuscular complication seen in critically ill patients - critical illness polyneuropathy. ${ }^{21,22}$ This condition differs from QM in three main aspects: (i) there is sensory involvement both clinically and electrophysiologically; (ii) dense fibrillations and positive sharp waves are seen in electromyography; and (iii) the muscle biopsy shows changes compatible with denervation. ${ }^{23}$ Effects of sepsis on muscle tissue varies from direct infection of the muscle (pyomyositis) to indirect ones, perhaps through cytokines, causing focal necrosis, muscle protein wasting and depletion of high energy phosphate reserves (for review see Bolton ${ }^{22}$ and Zochodne $^{24}$ ). It is possible that QM is part of a spectrum of changes that occur in muscle tissue under various conditions including: sepsis, multi-organ failure, exposure to steroids and/or NDMBAs.

Addendum: Since the initial submission of this article we have become aware of two other studies in which patients developed acute quadriplegic myopathy without significant exposure to steroids or neuromuscular blocking agents. ${ }^{25,26}$

\section{ACKNOWLEDGEMENTS:}

Anita Thiessen provided technical assistance with the electrophysiological studies. A.H. is a Clinical Research Fellow and D.W.Z. is a Medical Scholar of the Alberta Heritage Foundation for Medical Research.

\section{REFERENCES:}

1. MacFarlane IA, Rosenthal FD. Severe myopathy after status asthmaticus. Lancet 1977;2:615.

2. Danon MJ, Carpenter S. Myopathy with thick filament (myosin) loss following prolonged paralysis with vecuronium during steroid treatment. Muscle Nerve 1991;14:1131-9.

3. McGill KC, Dorfman LJ. Automatic decomposition electromyography (ADEMG): validation and normative data in brachial biceps. Electroencephalogr Clin Neurophysiol 1985;61:453-61.

4. Van Marle W, Woods KL. Acute hydrocortisone myopathy. Br Med J 1980;281:271-2.

5. Helliwell TR, Coakley JH, Wagenmakers AJ, Griffiths RD, Campbell IT, Green CJ, et al. Necrotizing myopathy in critically ill patients. J Pathol 1991;164:307-14.

6. Ramsay DA, Zochodne DW, Robertson DM, Nag S, Ludwin SK. A syndrome of acute severe muscle necrosis in intensive care unit patients. J Neuropathol Exp Neurol 1993;52:387-98.

7. Zochodne DW, Ramsay DA, Saly V, Shelley S, Moffatt S. Acute necrotizing myopathy of intensive care: electrophysiological studies. Muscle Nerve 1994;17:285-92.

8. Lacomis D, Giuliani MJ, Van Cott A, Kramer DJ. Acute myopathy of intensive care: clinical, electromyographic, and pathological aspects. Ann Neurol 1996;40:645-54.

9. Matsubara S, Okada T, Yoshida M. Mitochondrial changes in acute myopathy after treatment of respiratory failure with mechanical ventilation (acute relaxant-steroid myopathy). Acta Neuropathol (Berl) 1994;88:475-8.

10. Fischer JR, Baer RK. Acute myopathy associated with combined use of corticosteroids and neuromuscular blocking agents. Ann Pharmacother 1996;30:1437-45.

11. al-Lozi MT, Pestronk A, Yee WC, Flaris N, Cooper J. Rapidly evolving myopathy with myosin-deficient muscle fibers. Ann Neurol 1994:35:273-9.

12. Hanson P, Dive A, Brucher JM, Bisteau M, Dangoisse $M$, Deltombe T. Acute corticosteroid myopathy in intensive care patients. Muscle Nerve 1997;20:1371-80.

13. Showalter CJ, Engel AG. Acute quadriplegic myopathy: analysis of myosin isoforms and evidence for calpain-mediated proteolysis. Muscle Nerve 1997;20:316-22.

14. Barohn RJ, Jackson CE, Rogers SJ, Ridings LW, McVey AL. Prolonged paralysis due to nondepolarizing neuromuscular blocking agents and corticosteroids. Muscle Nerve 1994;17:64754.

15. Rich MM, Teener JW, Raps EC, Schotland DL, Bird SJ. Muscle is electrically inexcitable in acute quadriplegic myopathy. Neurology 1996;46:731-6.

16. Rich MM, Bird SJ, Raps EC, McCluskey LF, Teener JW. Direct 
muscle stimulation in acute quadriplegic myopathy. Muscle Nerve 1997;20:665-73.

17. Hirano M, Ott BR, Raps EC, Minetti C, Lennihan L, et al. Acute quadriplegic myopathy: a complication of treatment with steroids, nondepolarizing blocking agents, or both. Neurology 1992;42:2082-7.

18. Massa R, Carpenter S, Holland P, Karpati G. Loss and renewal of thick myofilaments in glucocorticoid-treated rat soleus after denervation and reinnervation. Muscle Nerve 1992;15:1290-8.

19. The Compendium of Pharmaceuticals and Specialties. Ottawa: Canadian Pharmaceutical Association, 1995.

20. Minetti C, Hirano M, Morreale G, Pedemonte M, Cordone G, et al. Ubiquitin expression in acute steroid myopathy with loss of myosin thick filaments. Muscle Nerve 1996;19:94-6.

21. Bolton CF. Neuromuscular complications of sepsis. Intensive Care Med 1993;19:S58-63.
22. Bolton CF. Sepsis and the systemic inflammatory response syndrome: neuromuscular manifestations. Crit Care Med 1996;24:1408-16.

23. Zochodne DW, Bolton CF, Wells GA, Gilbert JJ, Hahn AF, et al. Critical illness polyneuropathy. A complication of sepsis and multiple organ failure. Brain 1987;110:819-41.

24. Zochodne DW, Bolton CF. Neuromuscular disorders in critical illness. Baillieres Clin Neurol 1996;5:645-71.

25. Deconinck N, Van Parijs V, Beckers-Bleukx G, Van den Bergh P. Critical illness myopathy unrelated to corticosteroids or neuromuscular blocking agents. Neuromuscular Disorders 1998;8:186-92.

26. Bolton CF, Ramsay DA, Rutledge F. Acute quadriplegic myopathy (AQM), sepsis and systemic inflammatory response syndrome (SIRS). Neurology 1998;50:242-3. 